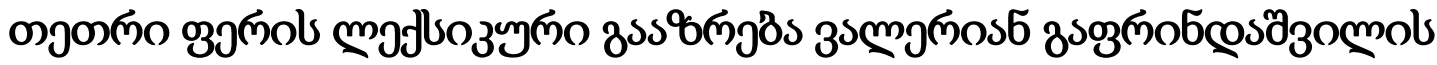

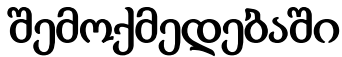

\author{
usbsos \%groce?

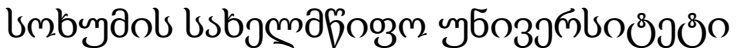

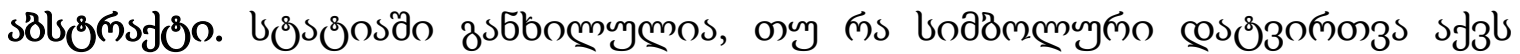

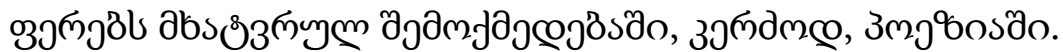

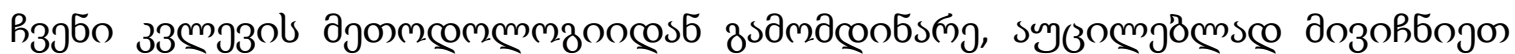

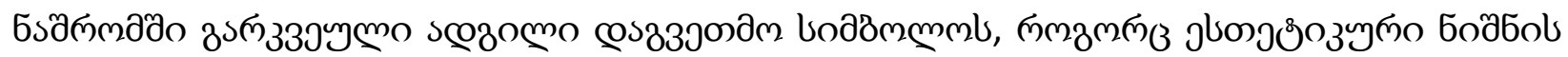

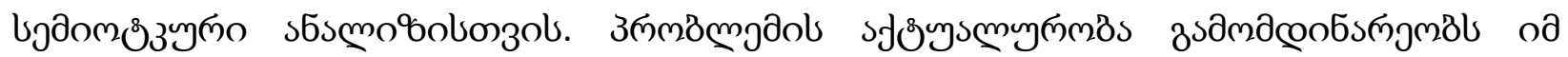

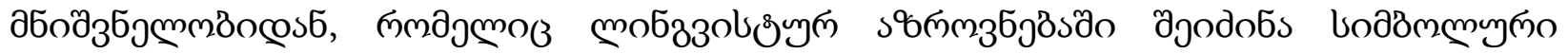

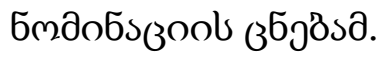

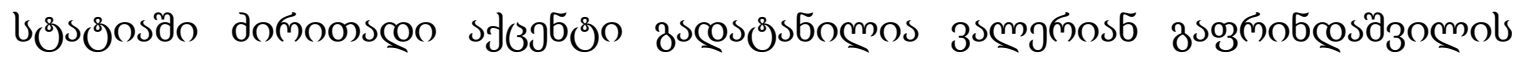
зmj

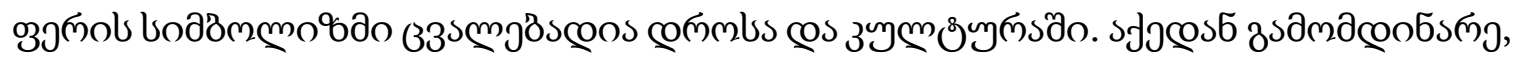

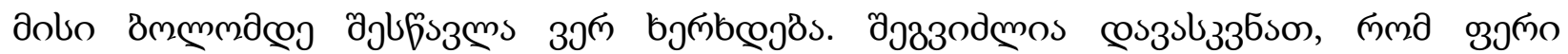

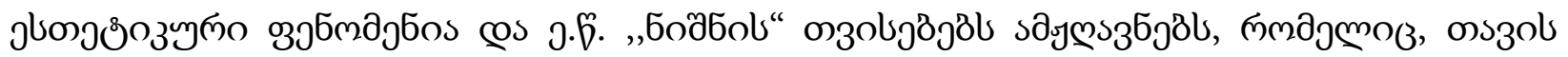

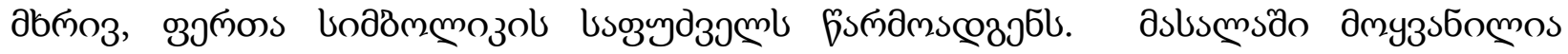

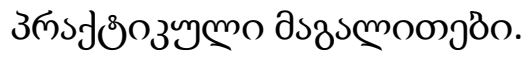

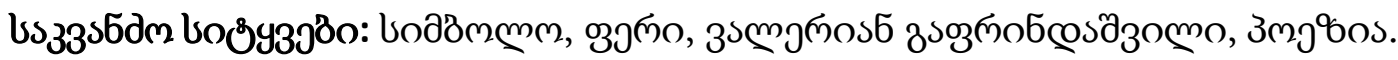

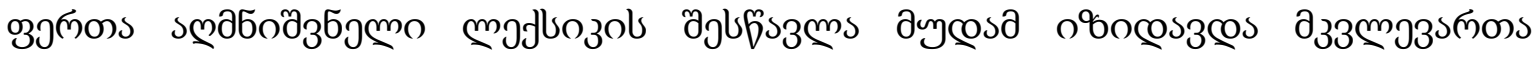

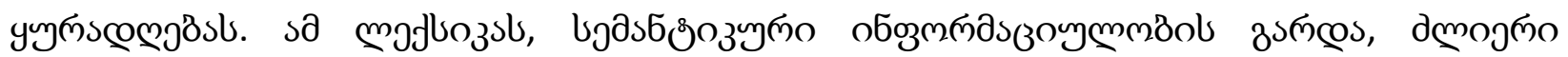

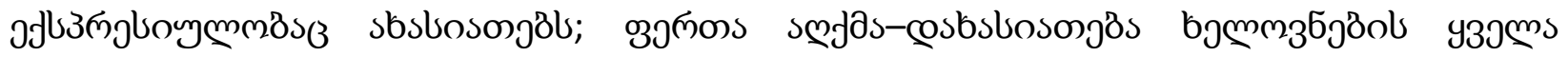

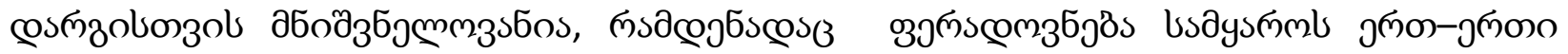

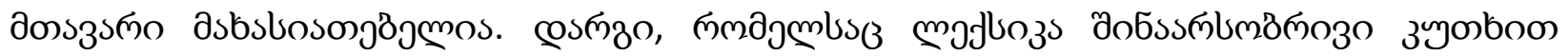

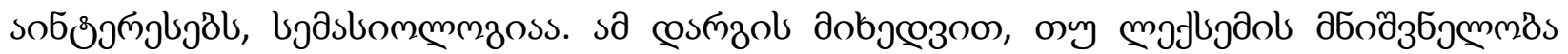

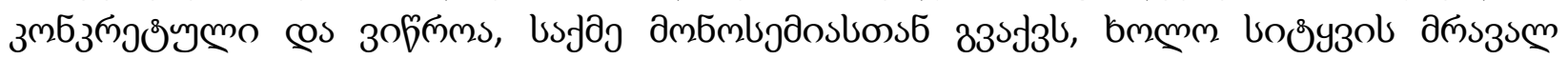

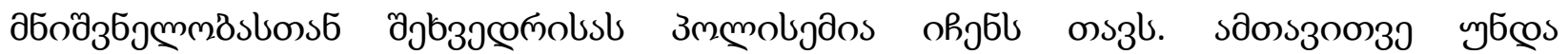

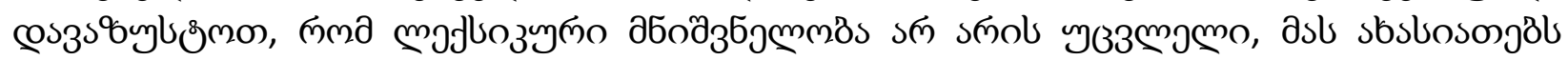

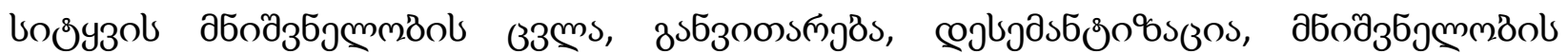

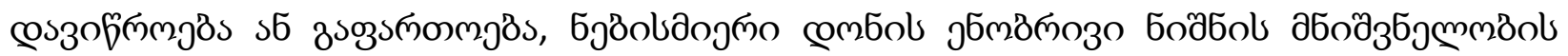

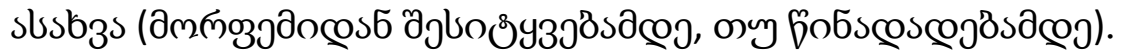

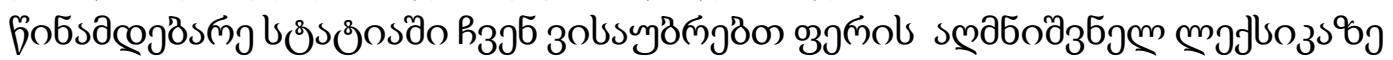

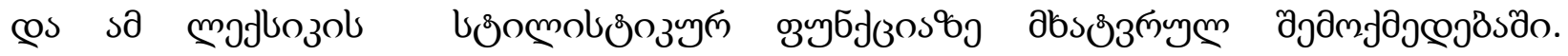




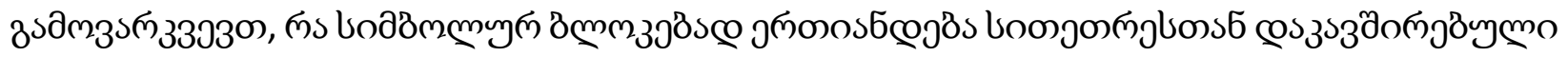

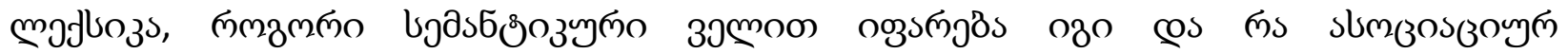
26одзб

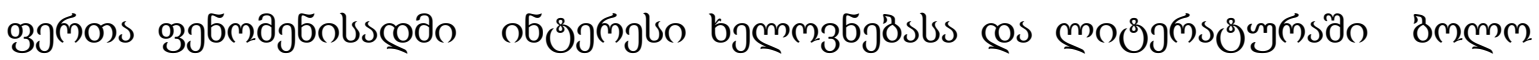

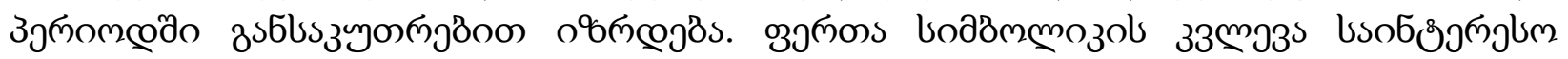

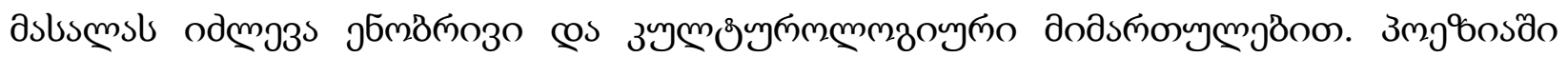

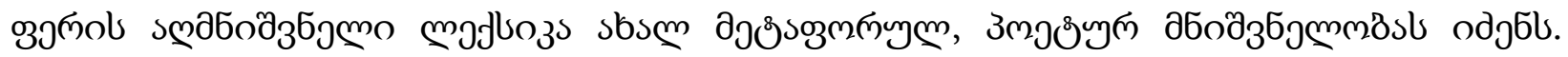

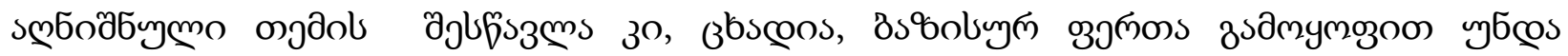

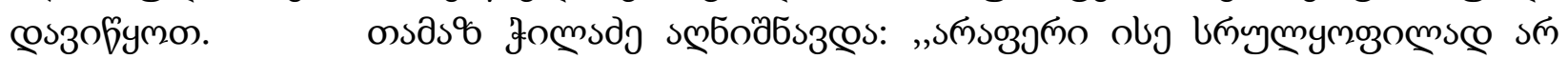

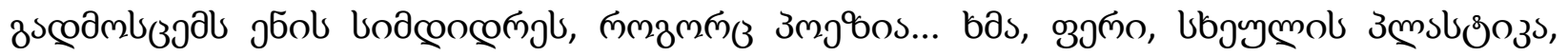

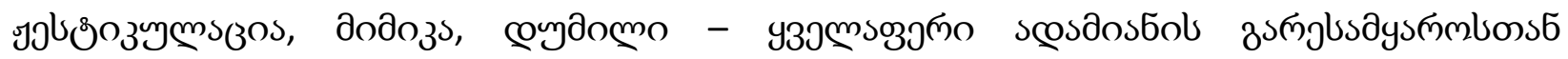

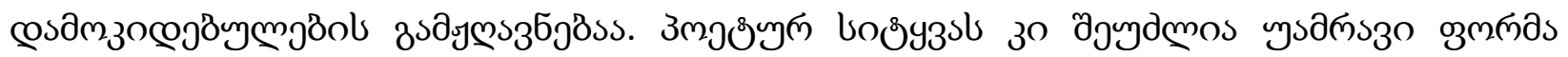

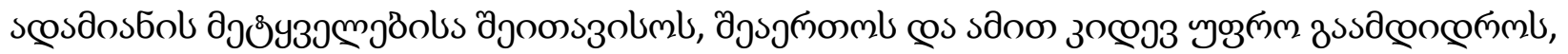

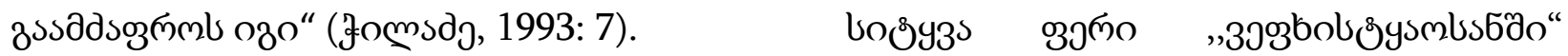

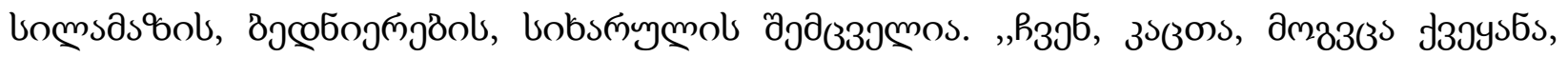

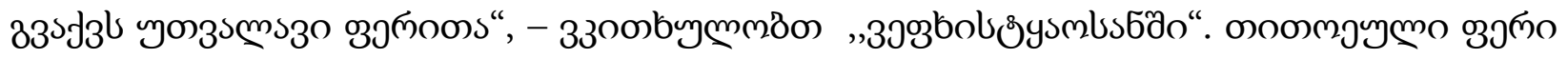

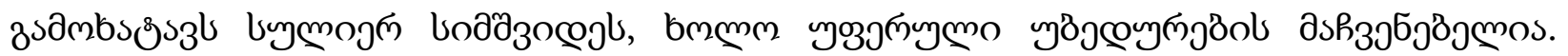

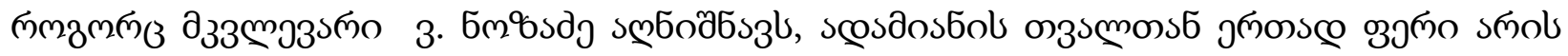

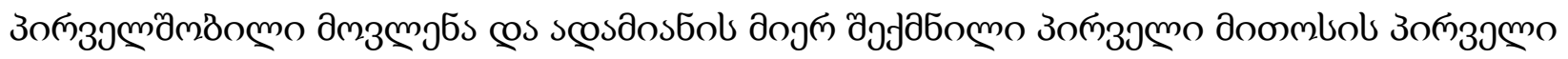

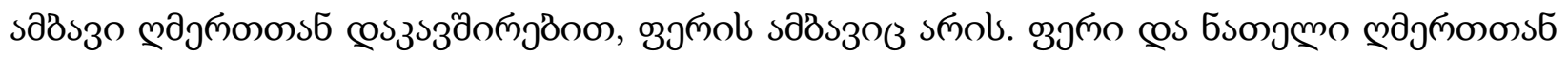

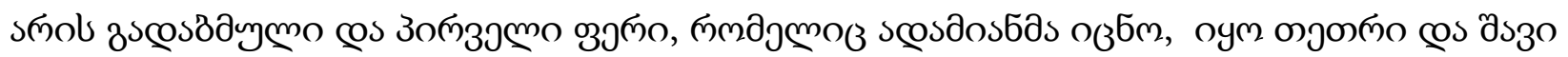
(Бm\&sdj, 1954: 8).

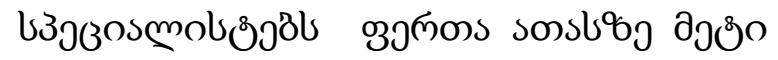

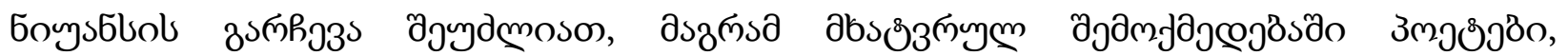

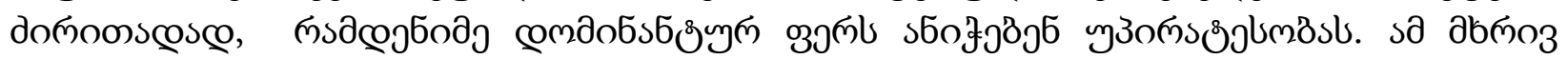

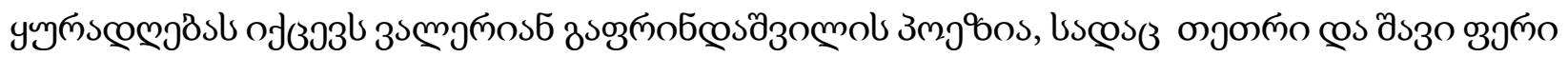

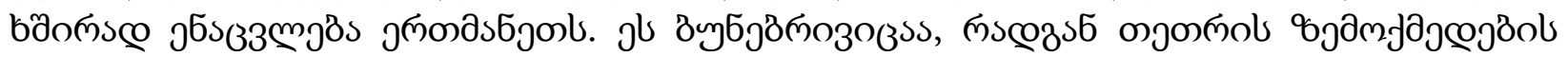

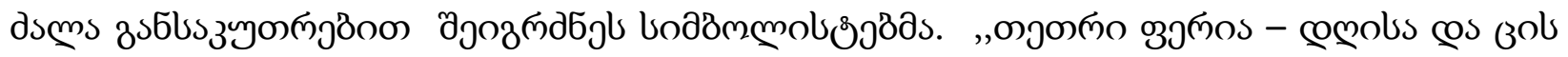

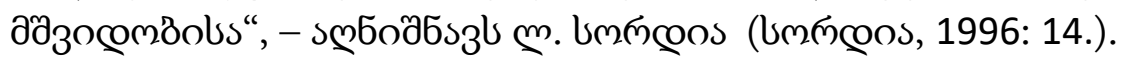

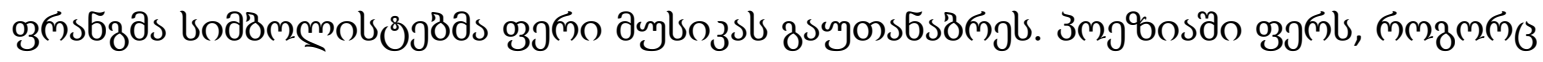

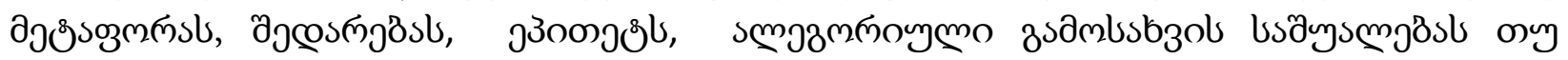

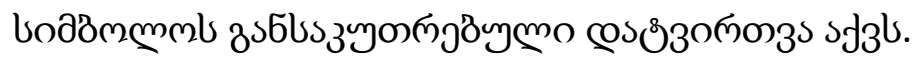

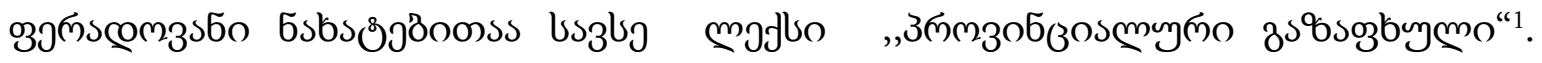

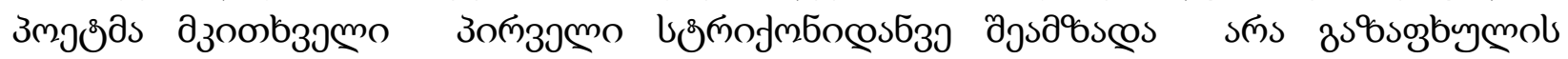

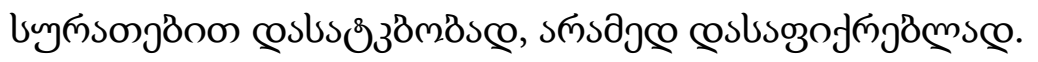

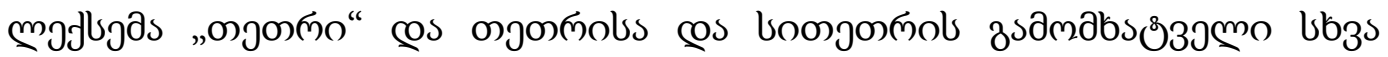
mлfl

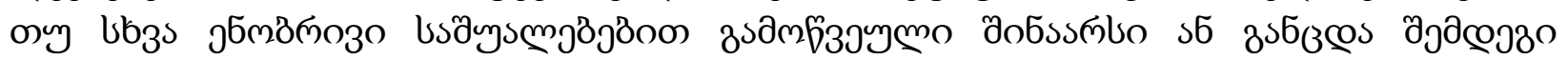

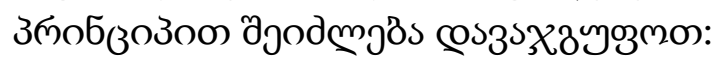

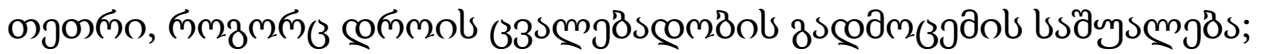

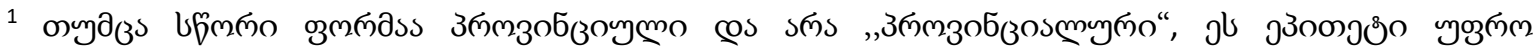

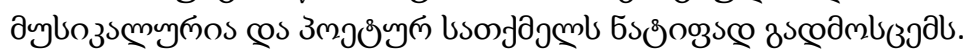




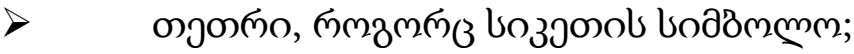

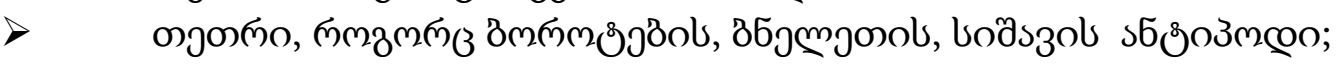

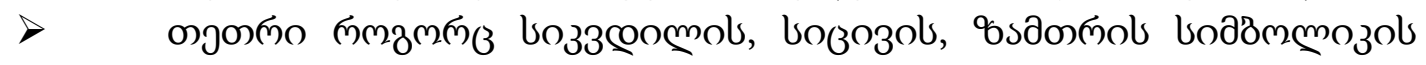

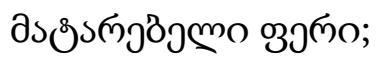

олопо, пмзмпъ одущо;

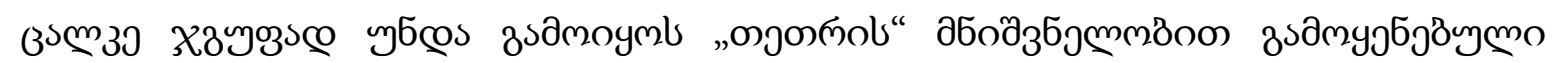

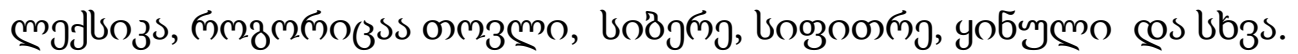

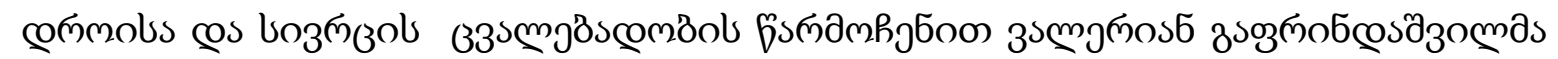

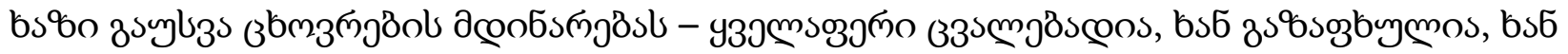

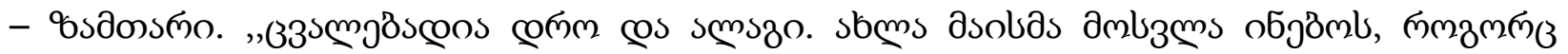

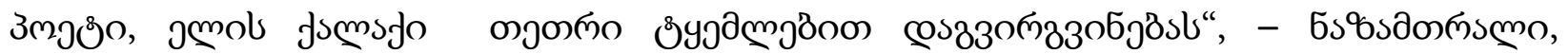

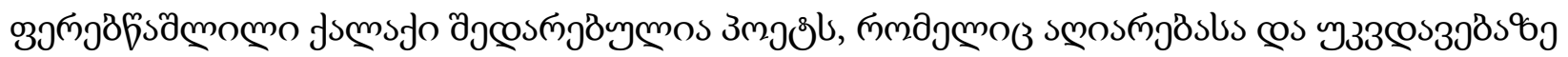

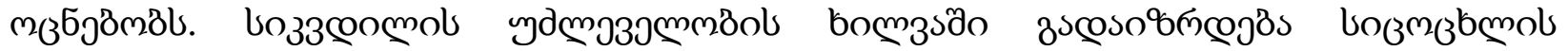

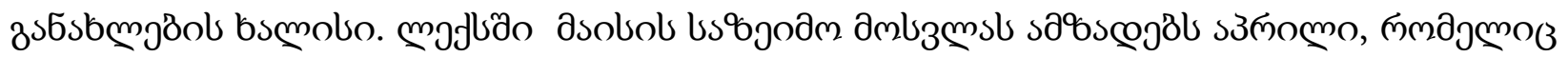

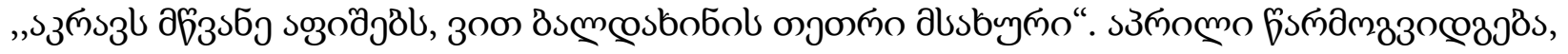

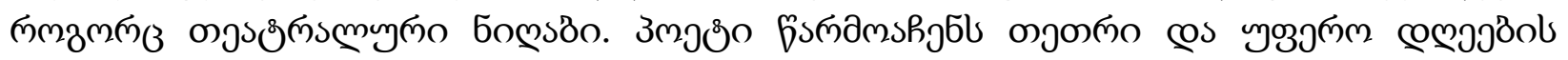

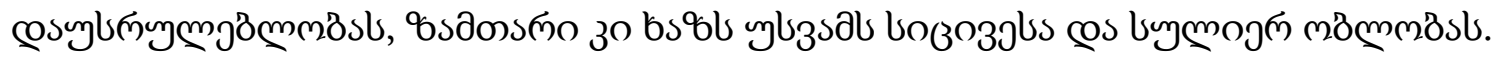

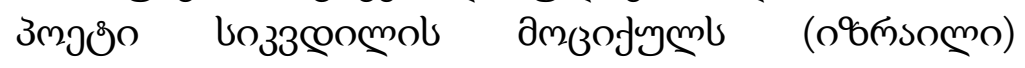

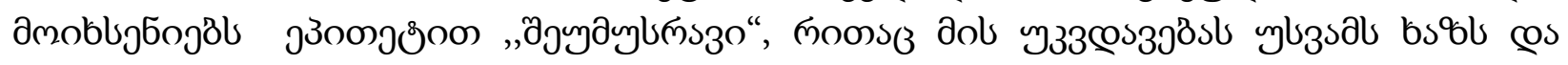

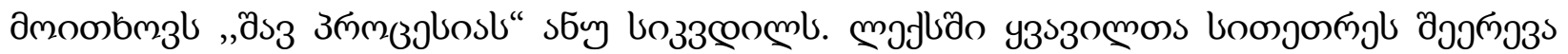

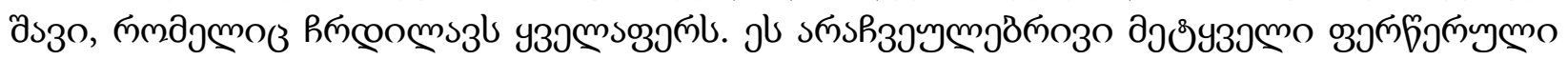

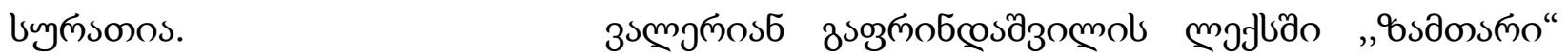

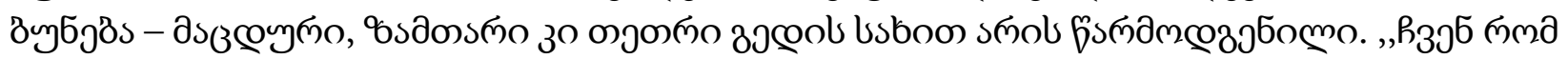

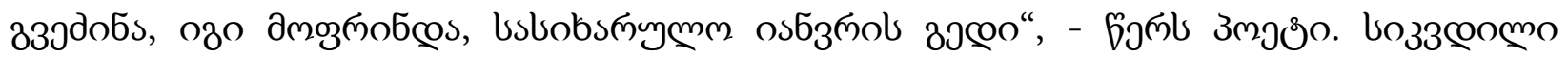

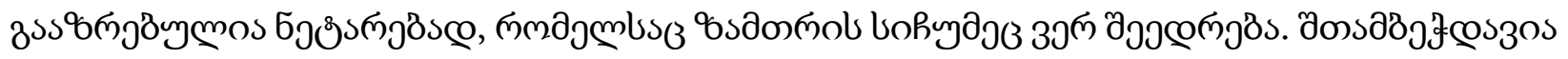

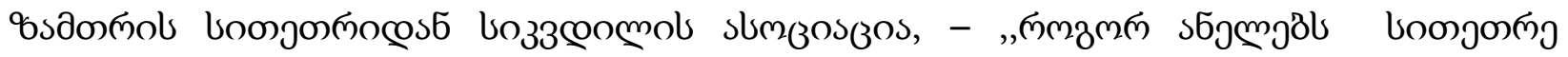

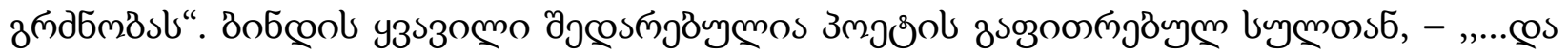

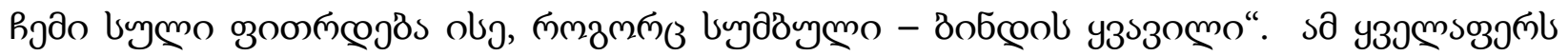

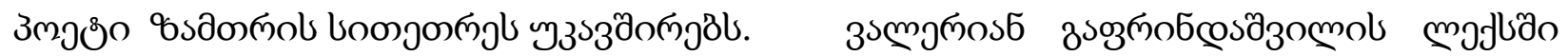

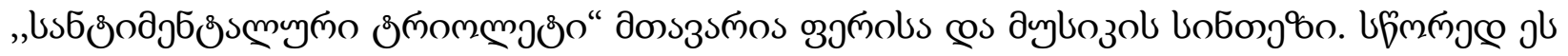

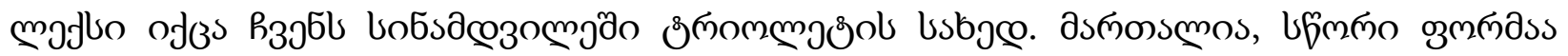

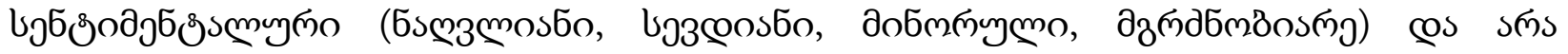

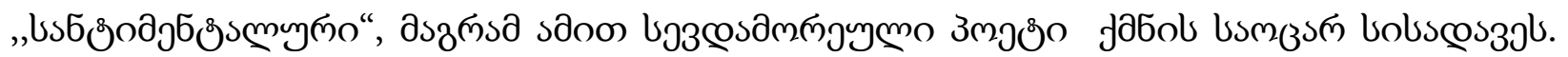

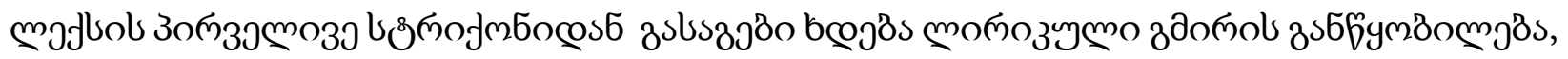

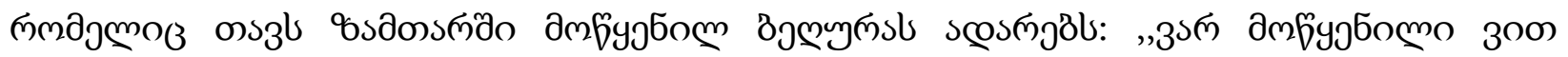

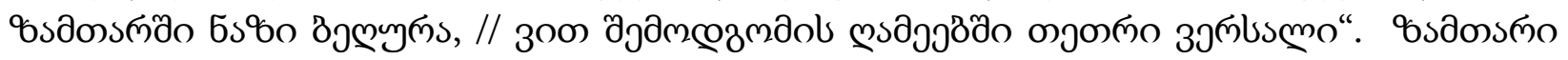

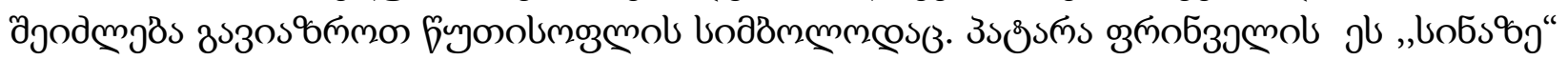

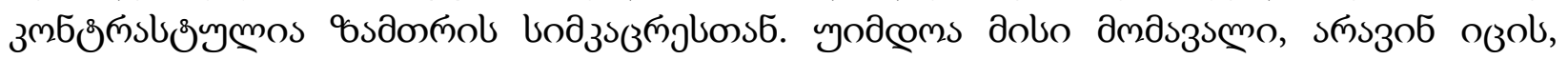

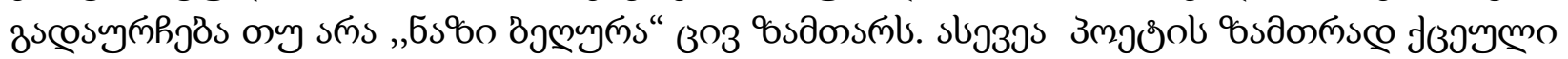

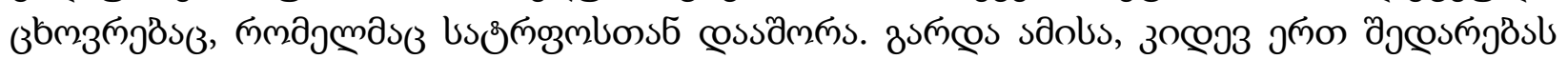

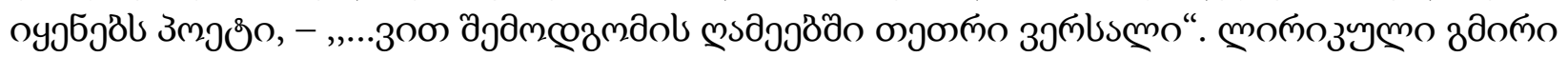

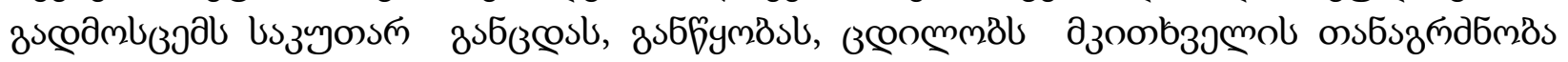




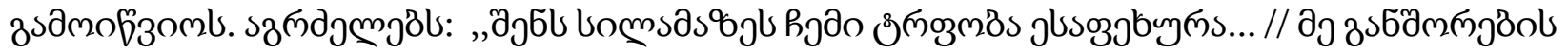
зозо омзмо cocobsbl ajbyns."

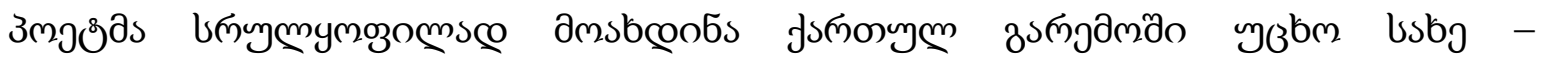

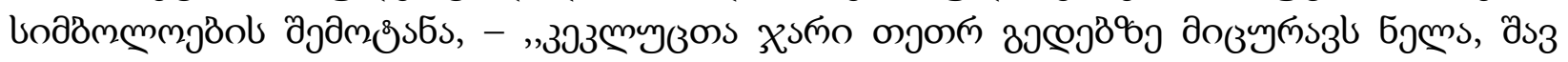

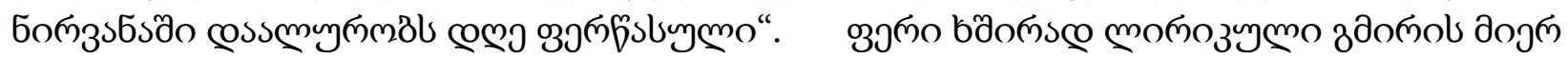

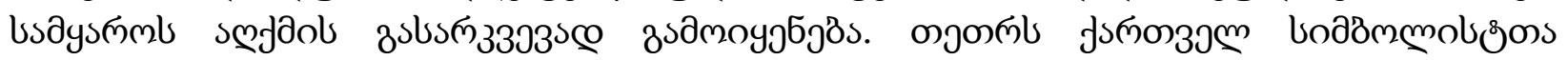

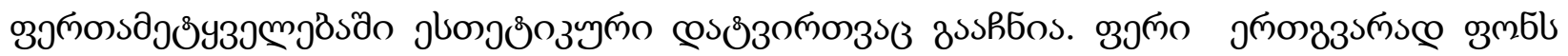

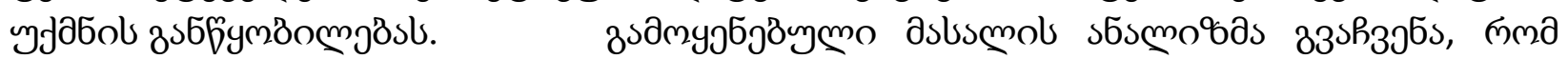

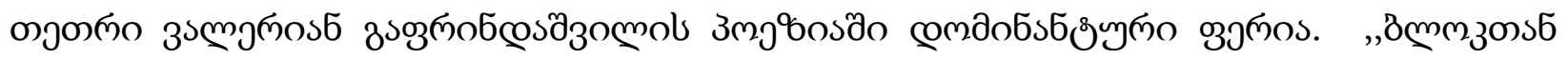

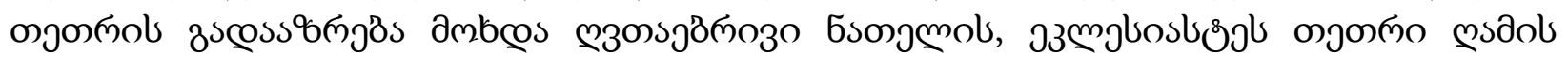

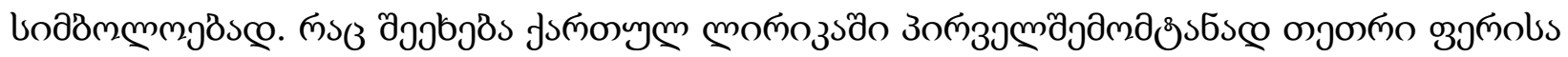

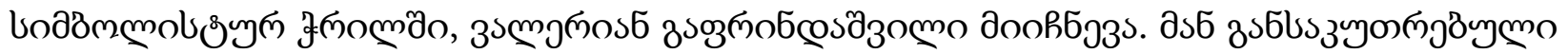

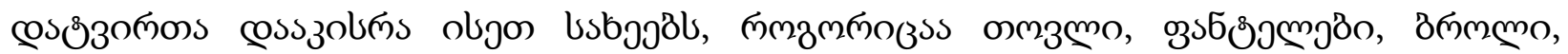

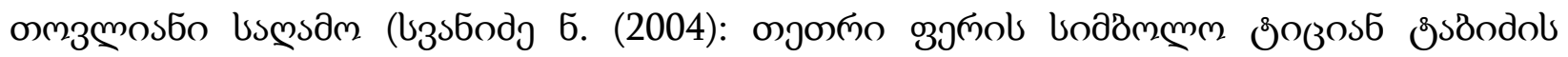

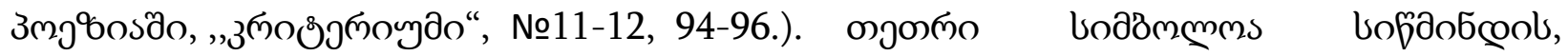

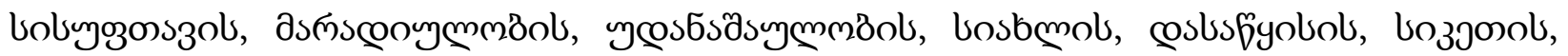

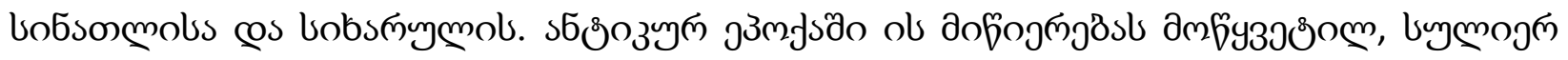

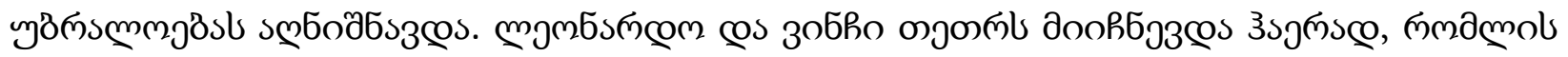

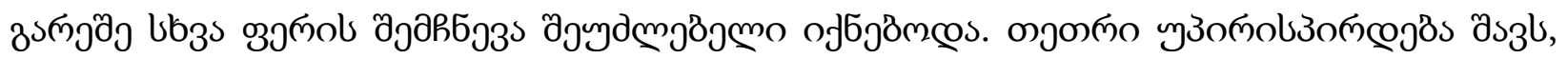

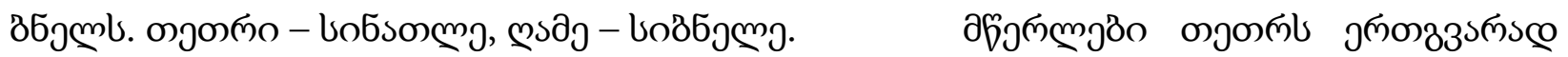

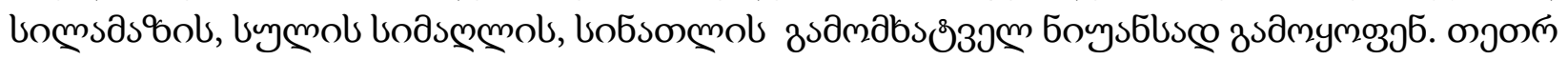

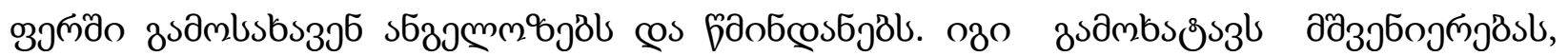

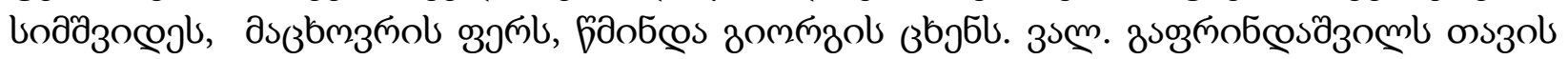

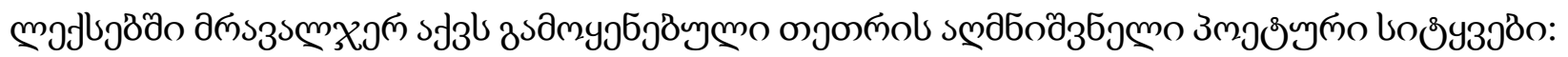

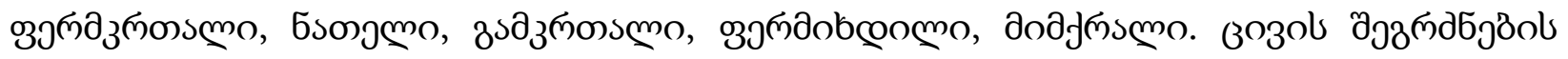

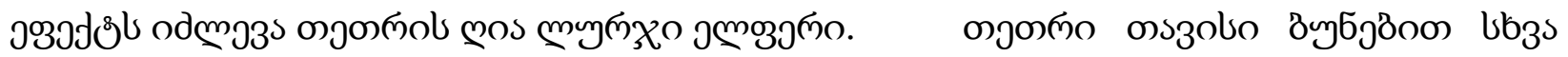

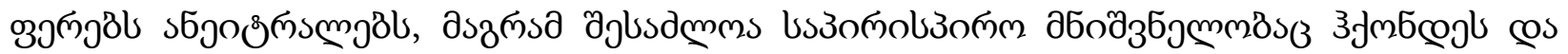

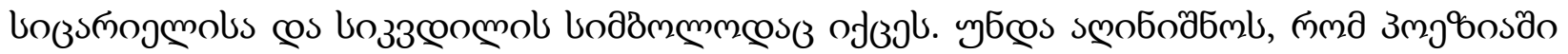

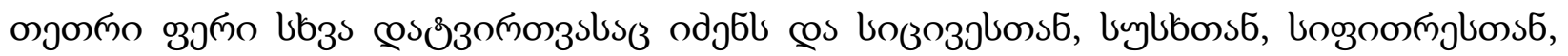

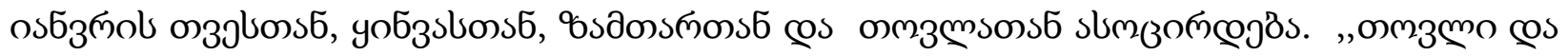

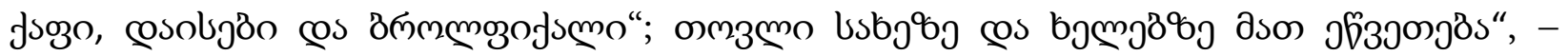

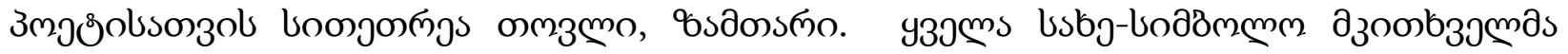

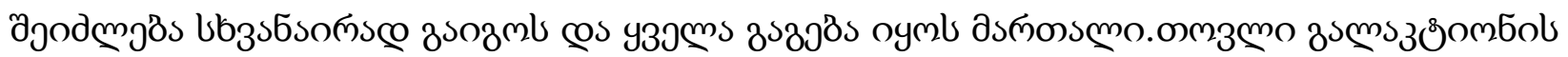

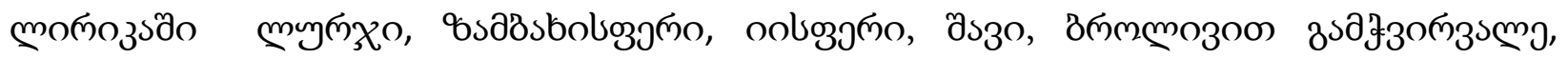

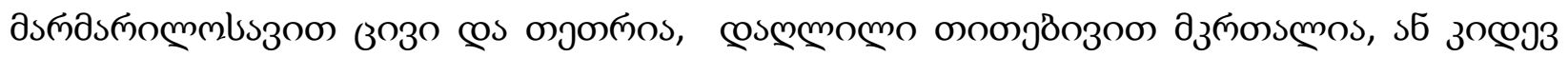

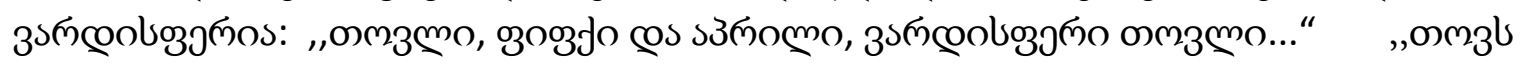

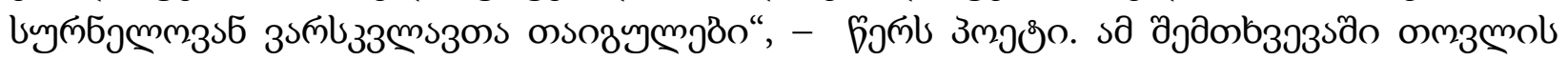

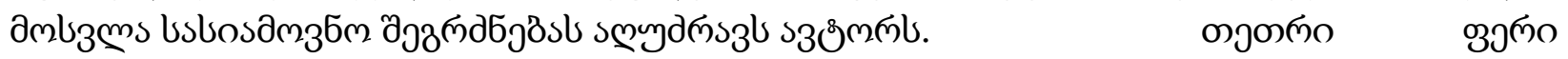

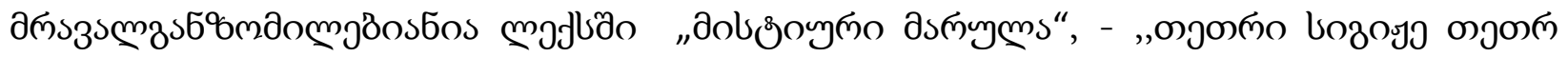

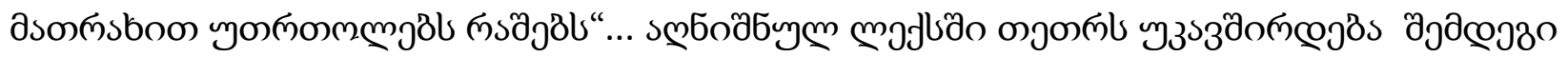

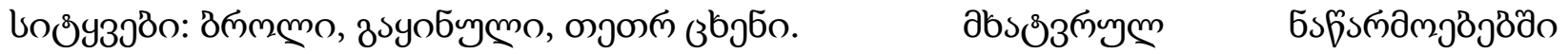

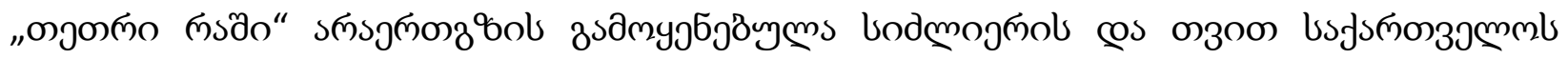




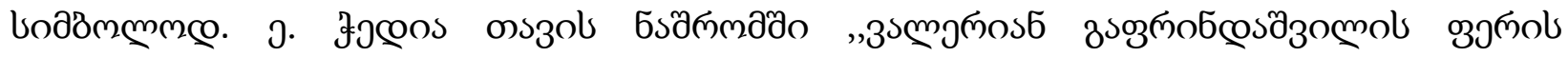

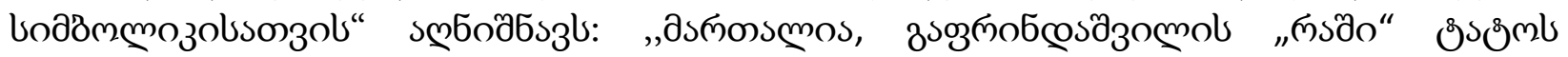

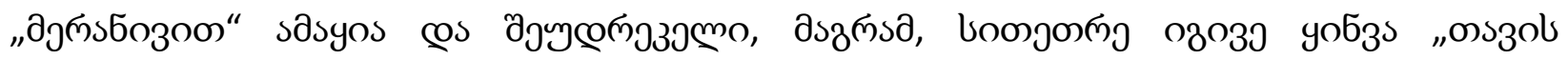

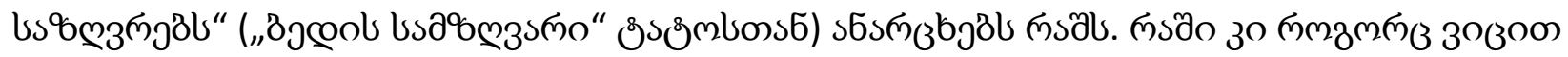

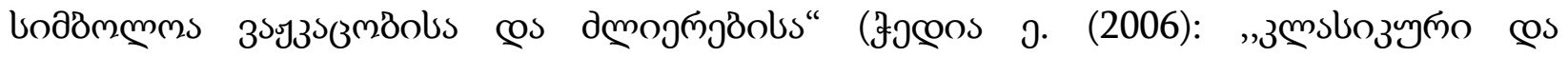

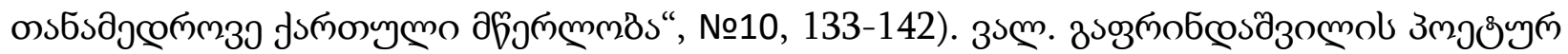

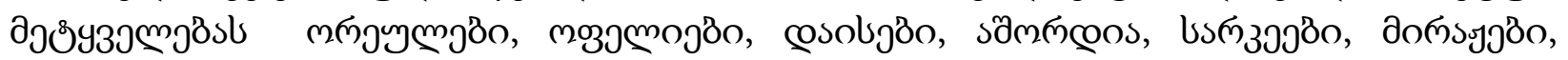

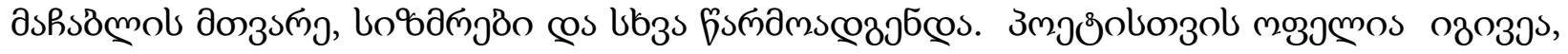

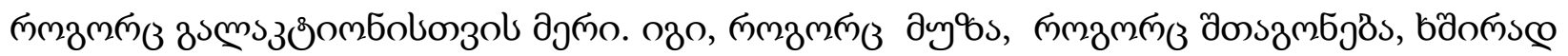

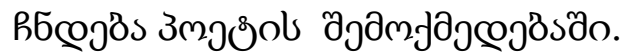

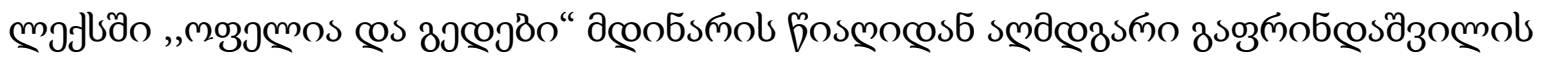

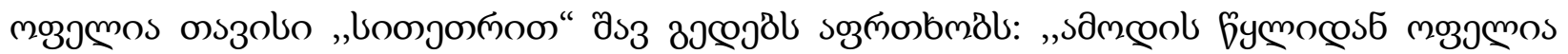

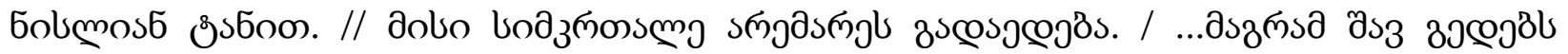

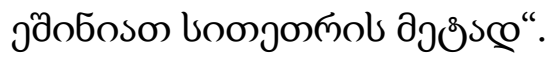

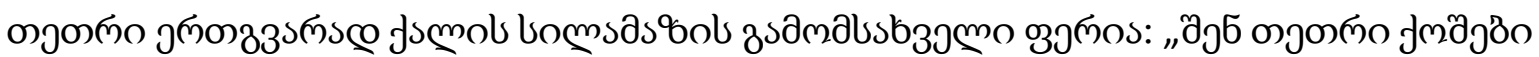

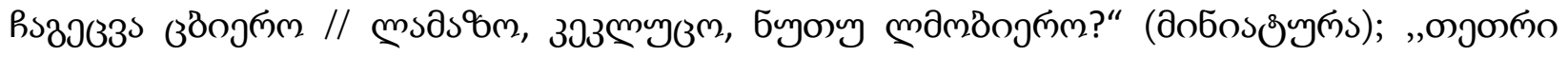

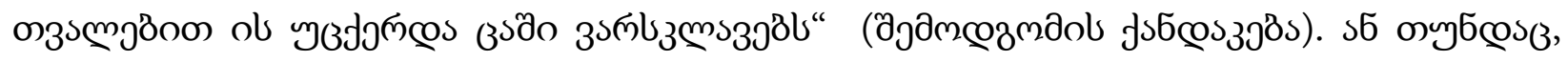

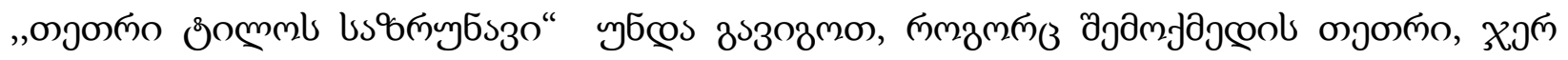

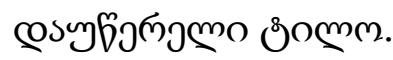

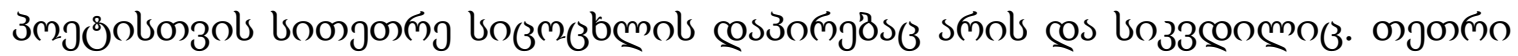

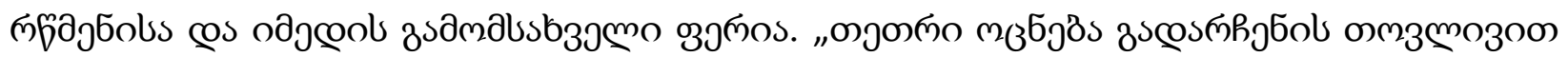

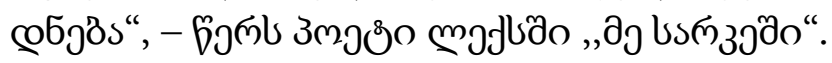

उзмmgnos6 дsоुпобœs

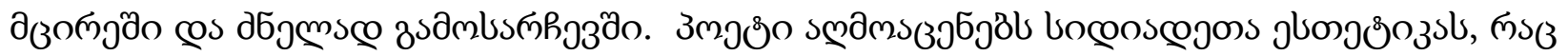

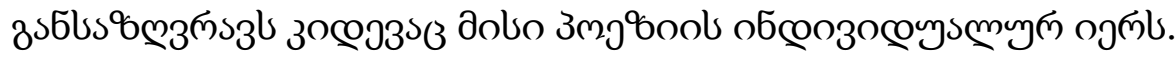

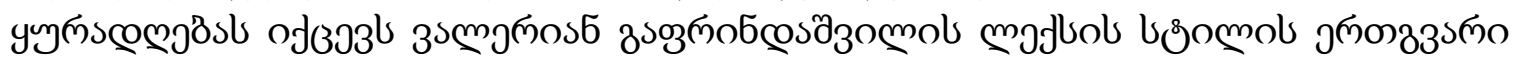

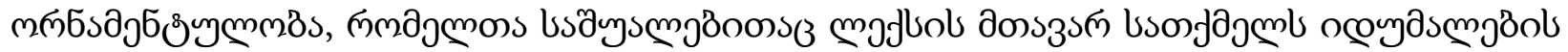

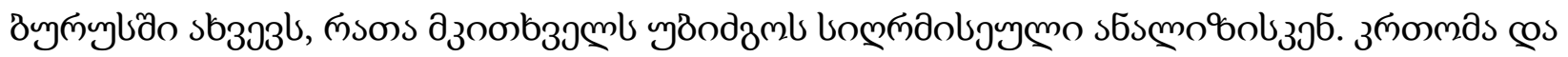

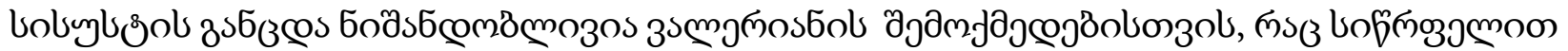

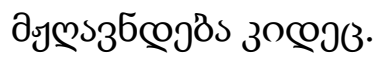

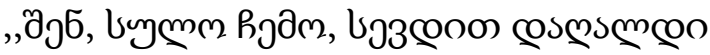

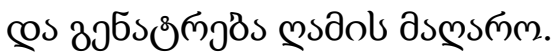

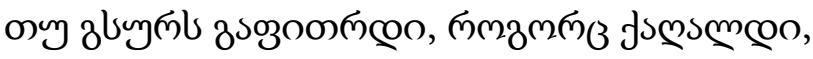

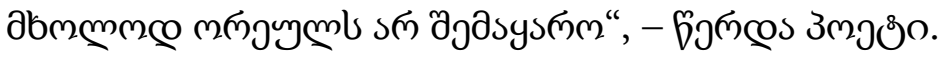

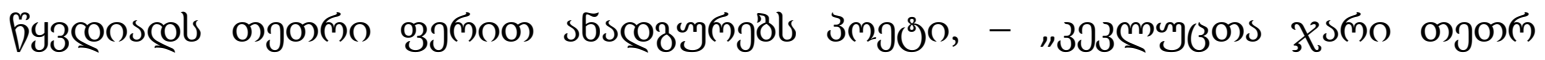

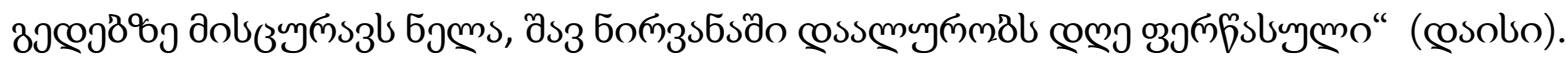

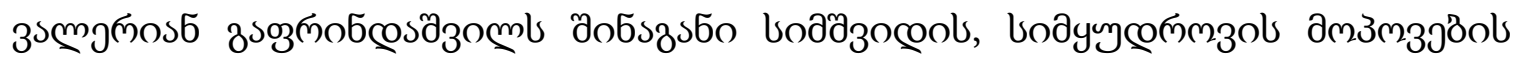

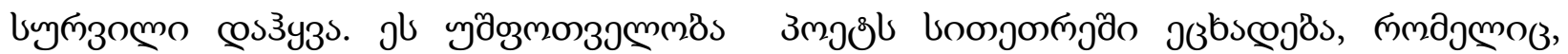

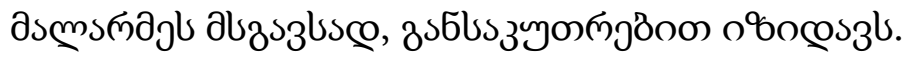

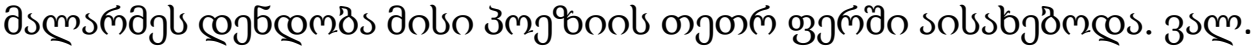

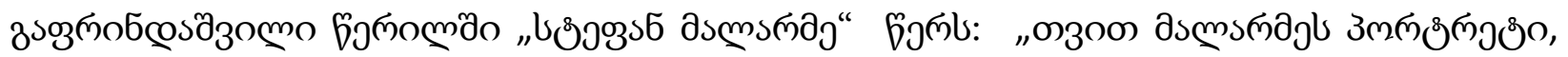

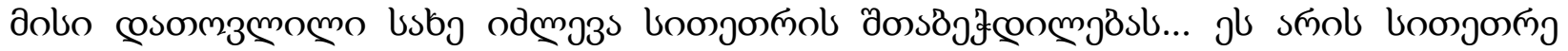

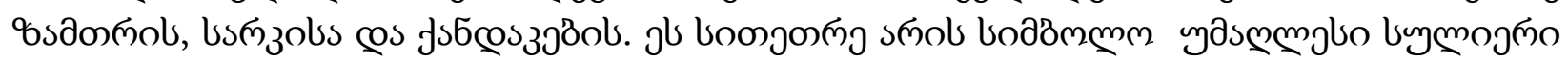




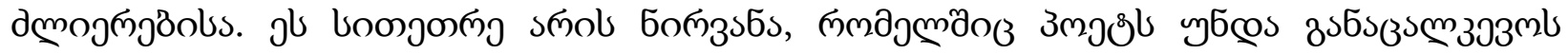

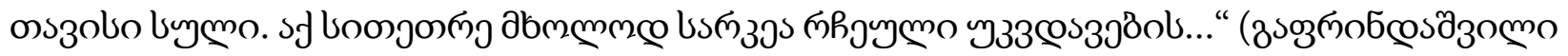

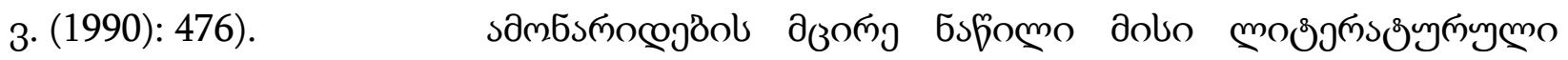

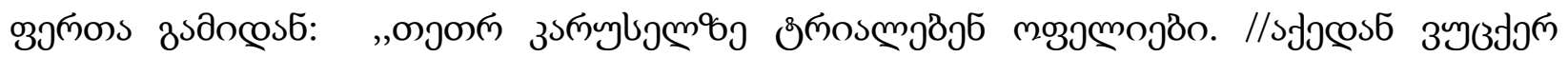

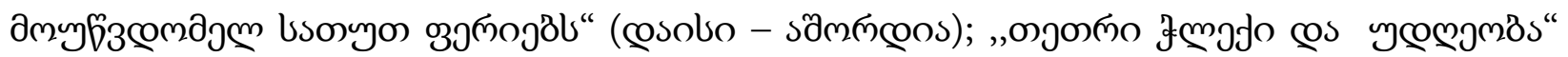

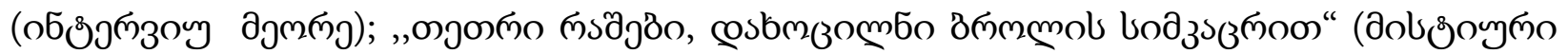

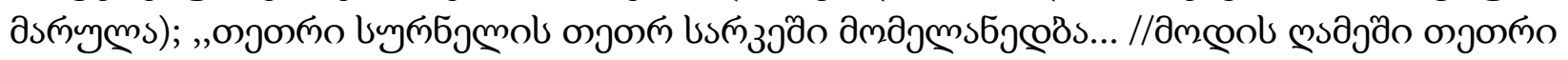

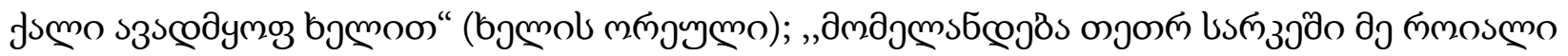

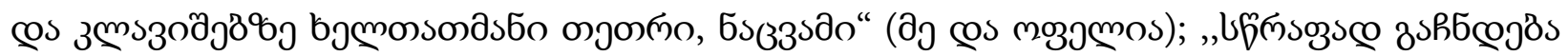

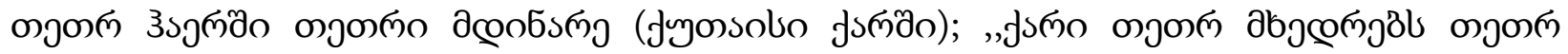

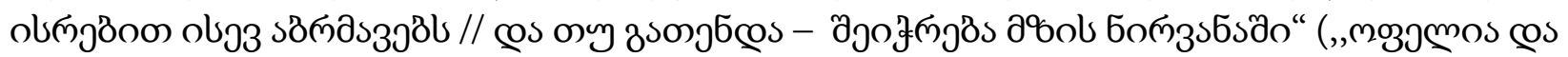

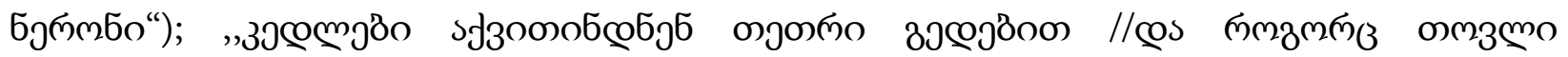

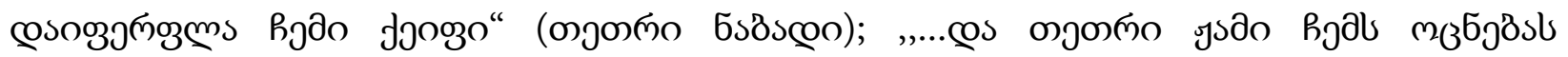

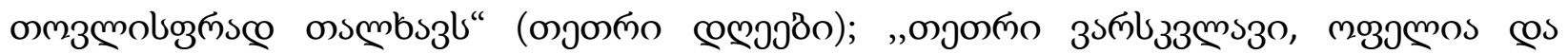
lobsஙூymo"...

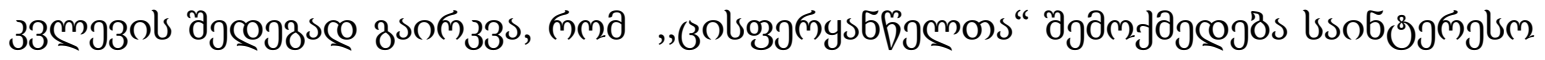

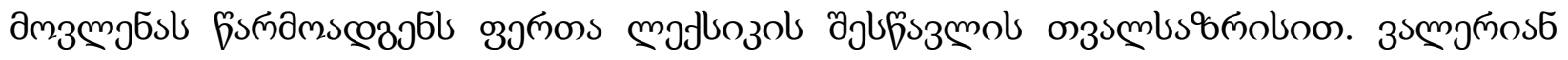

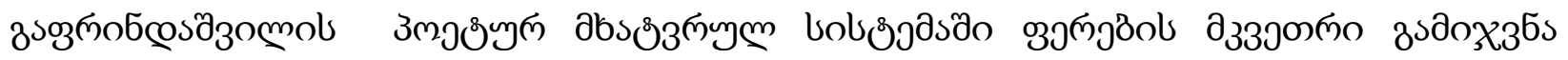

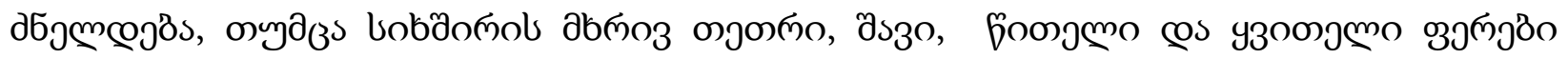
зsдмопһวзоьб.

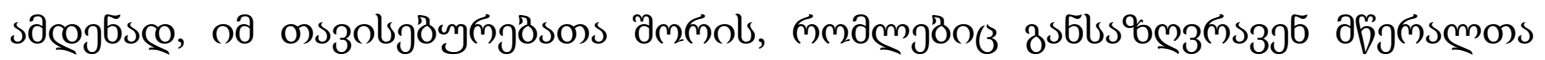

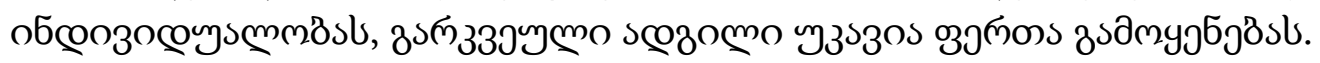

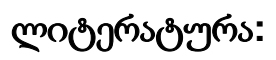

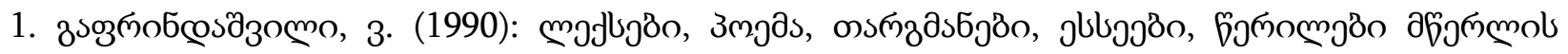

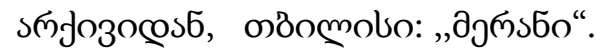

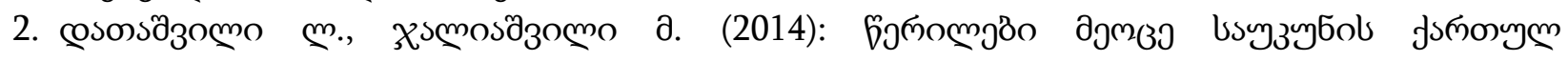

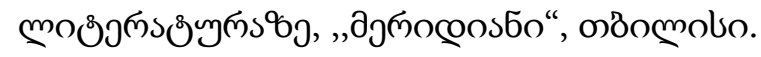

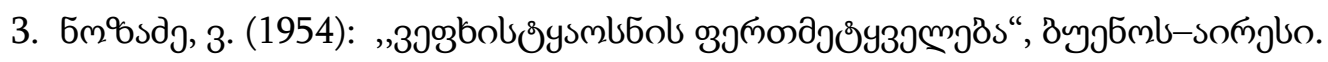

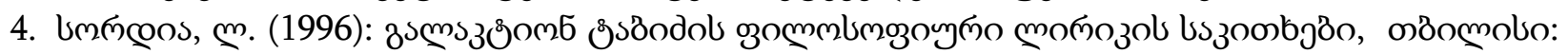

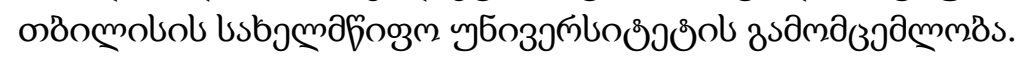

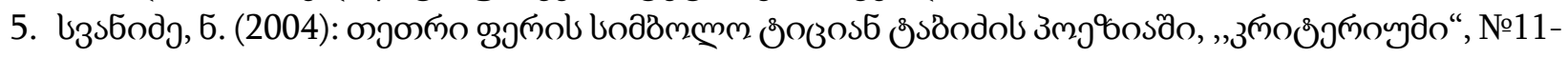
12. 94-96.

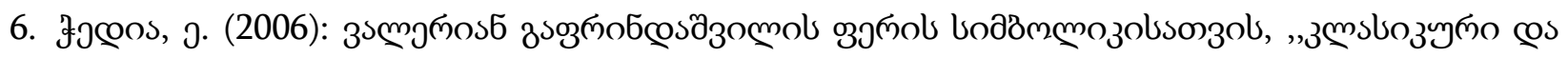

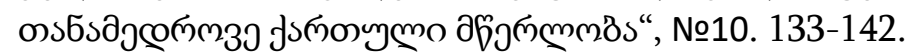

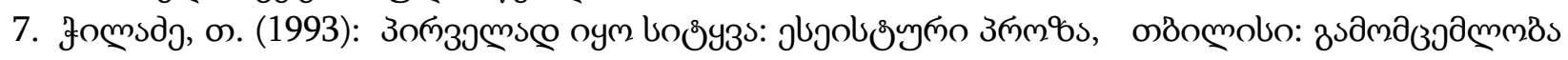

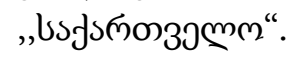

8. Әऽ London, 1996.

9. Internet resourses:

http://www.spekali.tsu.ge/index.php/ge/article/viewArticle/4/34 http://www.mutablesound.com/home/?p=2165 


\title{
Understanding of White Color in the Art of Valerian Gaprindashvili
}

\author{
Sanaia Pheride \\ Sokhumi State University
}

\begin{abstract}
The article "Understanding of White Color in the Art of Valerian Gaprindashvili" analyses what symbolic weight colour have in belletristic works, especially in poetry.

In the paper the main attention is drown on sensation of color in Valerian Gaprindashvili's creativity. Color as comparison, as epithet, as metaphor, symbol and manner of allegoric description has exclusive charge in the artistic and cogitative system of any great creator.

The aim of the article is colours' structural-semantic analyze and to gain argumentive materials.

The theme is actual because nowadays the interest on colour indicating vocabulary is increasing and Georgian linguists paid their attention on it as well.

The survey showed that Georgian symbolists were very interesting phenomena in studing colors. Color artistic analyze has an important part in Valerian Gaprindashvili works. White color dominates in poesy of Val. Gaphrindashvili. As a result of analyzing the symbolism of colors white color is considered as a symbol of light. In some cases white color is symbol of coldness, austerity and in other ones is symbol of concinnity. One can meet black, red, blue, green and yellow colors as well that have semantic charge in his poetry.

Color symbols are changeable through time and culture. According to this studying the theme fully is not possible. We can summarize that color is esthetic phenomena and reveals the traits of so called "mark" which is the foundation of color symbols.
\end{abstract}

Key words: Symbol, Color, Valerian Gaprindashvili, Poetry 